\title{
Individual differences in working memory capacity and learning: Evidence from the serial reaction time task
}

\author{
NASH UNSWORTH and RANDALL W. ENGLE \\ Georgia Institute of Technology, Atlanta, Georgia
}

\begin{abstract}
High and low working memory (WM) capacity individuals performed the serial reaction time task under both incidental and intentional learning conditions to determine the role of WM capacity in the learning of sequential information. WM capacity differences emerged in conditions of intentional but not incidental learning, indicating that individual differences in WM capacity occur in tasks requiring some form of control, with little difference appearing on tasks that required relatively automatic processing. Furthermore, an index of learning was significantly related to a measure of general fluid intelligence under intentional conditions only. Thus, the degree of learning was significantly related to higher order cognition, but only when intentional processing was emphasized.
\end{abstract}

Much of the learning that occurs day to day can be conceived of as incidental. We may not intentionally attempt to learn information, but regularities in the environment may be learned via an unconscious associative mechanism. This type of learning is generally referred to as implicit learning, which is typically considered to be complex learning that occurs via incidental processing in which a person is unaware of such learning (Buchner \& Wippich, 1998; Seger, 1994). Even though many environmental regularities can be learned incidentally, there are certainly times when intentional learning is desired or even required for accurate performance. Although one may be able to incidentally learn grammar rules, for instance, it may be desirable to actively engage in intentional learning to get a grasp of the intricacies of the language. Intentional learning is generally assumed to require some form of cognitive control (Posner \& Snyder, 1975; Schneider \& Shiffrin, 1977), whereas incidental learning can be seen as occurring in a rather automatic fashion.

This article focuses on the extent to which individual differences in working memory (WM) capacity are related to the degree of learning of a sequential pattern. Current views of WM capacity suggest that it is important in situations that require control but not in those involving automatic processing (Conway \& Engle, 1994; Rosen \& Engle, 1997). For example, studies have shown that WM capacity is important for learning in a variety of

We are grateful to Jessica Parsons and Lacy West for data collection assistance and to Rich Heitz for many helpful discussions in all phases of this project. This work was supported by Grant F49620-00-1-131 from the Air Force Office of Scientific Research. Correspondence should be addressed to N. Unsworth, School of Psychology, 654 Cherry St., Georgia Institute of Technology, Atlanta, GA 30332-0170 (e-mail: gtg039d@prism.gatech.edu) or to R. W. Engle, School of Psychology, 654 Cherry St., Georgia Institute of Technology, Atlanta, GA 303320170 (e-mail: randall.engle@psych.gatech.edu). situations such as complex learning (Kyllonen \& Stephens, 1990) and computer programming (Shute, 1991). However, these studies assessed the degree of learning under explicit, not incidental, learning conditions. In this article, we explore the extent to which WM capacity is important for learning under both incidental and intentional learning conditions, comparing them directly.

\section{Individual Differences in WM Capacity}

Engle, Tuholski, Laughlin, and Conway (1999; see also Engle, 2001) view WM as a highly activated subset of long-term memory (LTM) units (see also Cowan, 1988, 1995), processes for achieving and maintaining activation (e.g., phonological loop, visuospatial sketchpad, etc.) and executive attention. The activation of these units is dependent on the executive attention component (e.g., similar to the central executive in Baddeley's [1986] model), which serves to maintain current task goals, to process incoming information, and to block external (i.e., environmental distractors) and internal (i.e., other unrelated LTM units) interference. When we talk about WM capacity, we refer to one aspect of WM: the executive attention component.

Furthermore, we have suggested that the executive attention component of the broader WM system drives the correlation between complex WM span measures and higher order cognition (Engle \& Kane, 2004; Heitz, Unsworth, \& Engle, 2004). Evidence for this claim comes from studies demonstrating that individual differences in WM capacity correspond to those in the ability to control attention. Participants are first prescreened on a WM span measure (typically Ospan; Turner \& Engle, 1989) and only those participants who score in the upper quartile (henceforth high spans) and lower quartile (low spans) of the WM span distribution are asked to participate. Participants are then required to engage in a low-level, or el- 
ementary, attention task to test for possible individual differences on that task.

For instance, Kane, Bleckley, Conway, and Engle (2001) and Unsworth, Schrock, and Engle (2004) demonstrated that high spans and low spans do not differ on relatively automatic prosaccade trials, but that low spans are both slower and more error prone on antisaccade trials that require the endogenous control of attention for accurate performance. Furthermore, Conway, Cowan, and Bunting (2001), utilizing a dichotic listening procedure, found that only $20 \%$ of high spans reported hearing their name in the unattended channel, whereas $65 \%$ of low spans reported hearing their name. These results suggest that individual differences in WM capacity are related to those in attentional control. Further evidence for this claim comes from studies demonstrating span differences in Stroop interference (Kane \& Engle, 2003), negative priming (Conway, Tuholski, Shisler, \& Engle, 1999), and enumeration (Tuholski, Engle, \& Baylis, 2001). By this logic, we should see that high and low spans do not differ on relatively automatic forms of information processing, but that differences will emerge when control of attention is necessary (Conway \& Engle, 1994; Rosen \& Engle, 1997; Tuholski et al., 2001).

\section{Incidental Learning of Sequential Information}

Evidence suggests that implicit learning occurs relatively automatically. The basic idea is that a person learns a complex set of rules or relations and that this occurs even when he or she is unaware of the learning and when learning occurs without intent. The assumption is that learning is accomplished with minimal attention (Frensch, Wenke, \& Rünger, 1999; Stadler, 1995). Thus, although one cannot say that implicit learning occurs in the complete absence of attention, a person need only use minimal attention to perform the given task and maintain the task goals in memory. The idea that attention is necessary for implicit learning is quite controversial in the current literature (Shanks, 2003).

Beginning with the work of Nissen and Bullemer (1987), researchers have argued that attention is needed for implicit learning tasks. Most of this research has relied on the use of the serial reaction time paradigm (SRT; Nissen \& Bullemer, 1987) and divided-attention paradigms, in which a person performs both an implicit learning task and a concurrent attention-demanding task. The SRT is a simple task in which participants are presented with a stimulus (usually an asterisk) at one of four prescribed locations on a computer screen. They are required to press a key corresponding to the location. The stimuli appear either in a predetermined sequence or at random. Reaction times (RTs) in the repeating sequence condition get significantly faster over trials. The increase in RT when one switches from the repeating sequence to a random sequence is generally interpreted as an index of the amount of learning that has occurred.

A common technique for testing the effects of divided attention on the SRT is to have participants perform a tone-counting task while also performing the SRT task. These experiments generally show that performance on an implicit learning task diminishes if a concurrent task is used, suggesting that attention is needed for implicit learning to occur (Cohen, Ivry, \& Keele, 1990; Nissen \& Bullemer, 1987). However, other researchers have proposed that the consequences of a secondary task do not necessarily demonstrate that attention is needed for learning in the SRT, but rather that the secondary task somehow compromises sequence learning by disrupting a specific learning mechanism (Curran \& Keele, 1993), by reducing the capacity of short-term memory (STM; Frensch \& Miner, 1994), or by disrupting the encoding of the sequence (Stadler, 1995).

For instance, Cohen et al. (1990) suggested that some types of sequences can be learned under attentional load, whereas others cannot. Specifically, sequences with unique associations in which one event in the sequence is positioned to always be followed by another event, tend to be learned even under dual-task conditions. Ambiguous sequences, however, in which there are no unique associations, tend not to be learned under dual-task conditions. That is, sequences in which an event is followed by one of two different events in different positions in the sequence are learned poorly under dual-task conditions. For example, in the sequence 4213142, 4 is always followed by 2 (unique association), but 1 can either be followed by 3 or 4 (ambiguous association). Curran and Keele (1993) suggested that the learning of unique sequences occurs without attention but that learning of ambiguous sequences requires an attentional mechanism.

\section{The Present Study}

The present study attempted to determine the role of WM capacity in both incidental and intentional learning conditions. Here, we draw heavily on Cowan's (1988, 1995) model, as well as on subsequent work performed by Frensch and Miner (1994) examining this model using the SRT paradigm. Cowan's $(1988,1995)$ model postulates a unitary memory system with three separate levels of activation. These differing levels of activation include LTM units that are currently inactive, LTM units that are active above some ambient activation level and are currently in STM, and memory units that are highly active and are in the current focus of attention. Furthermore, Cowan's $(1988,1995)$ model suggests that a central executive mechanism guides the focus of attention during voluntary processing.

Frensch and Miner (1994) examined how Cowan's (1988) idea that STM is an activated subset of LTM units is related to implicit learning, as well as to individual differences in STM span. Similar to the ideas presented here, Frensch and Miner assumed that implicit learning is not dependent upon the central executive component and thus is not within the focus of attention. Accordingly, they argued that implicit learning occurs due to a passive associative learning mechanism that detects environmental covariations. For the appropriate associa- 
tions to be made, items must be simultaneously activated in STM. Thus, any experimental manipulation that prevents these associations from being active at the same time should result in reduced learning. In support of this claim, Frensch and Miner demonstrated that incidental learning of the sequence occurred more readily when the response-stimulus interval (RSI) was $500 \mathrm{msec}$, as opposed to 1,500 msec (Experiments 1 and 2). They argued that this manipulation affected activation levels by decreasing the time in which associations could be made in the activated portion of LTM and thus led to reduced implicit learning. Furthermore, Frensch and Miner found that STM span measures were reliably correlated with an indirect measure of learning under intentional and dualtask learning conditions with an RSI of $500 \mathrm{msec}$. On the basis of this finding, they suggested that STM capacity only influences implicit learning when the capacity of STM is reached. Thus, implicit learning can be viewed as a passive association of the subset of activated LTM units, whereas explicit learning occurs due to an active associative mechanism directed by the central executive and in the highly activated subset of LTM units that are within the focus of attention.

With this framework in mind, we explored the role of WM capacity under both incidental and intentional learning conditions. The question guiding this study was whether high- and low-span differences are due to differential learning ability per se, or whether differences only occur when attentional control is brought to bear on learning. If WM span measures index the efficacy of the entire WM system (i.e., activation levels, STM capacity, representational coding, etc.), we should see that high and low spans differ in the degree to which they learn the repeating sequential pattern. If, however, WM capacity indexes the efficacy of only one component of the WM system (i.e., the central executive/executive attention), we should see that high and low spans show equivalent patterns of implicit learning. Learning should occur for both span groups, but no differences should emerge. Based on the framework of Cowan $(1988,1995)$ and Frensch and Miner (1994), central executive resources should be needed under intentional learning instructions to guide the focus of attention and engage in hypothesis testing. Thus, making the task instructions intentional should result in span differences in the degree of learning, in which high spans demonstrate more learning than do low spans.

To assess these predictions, we tested high and low spans on a typical version of the SRT task. Learning of the sequential pattern was assessed by examining the decrease in RT across the five blocks in which the pattern repeated itself. Another measure of learning was an examination of the difference between sequential and random blocks of trials. Previous research (e.g., Stadler, 1995) has demonstrated that, as participants switch from blocks of repeating trials to blocks of random trials, a large increase in RT is observed. Finally, we assessed the level of awareness via two paper-and-pencil measures. If one span group were to demonstrate more learning under incidental conditions, it is important to show that this difference is not due to that group being more aware of the pattern than the other group. Therefore, participants were classified as being either unaware or aware, and high and low spans were compared to assess any potential differences.

\section{METHOD}

\section{Participant Screening for WM Capacity}

The participants were prescreened for WM capacity using the operation span task (Ospan; Turner \& Engle, 1989). The Ospan has demonstrated good reliability and validity (Engle et al., 1999; Klein $\&$ Fiss, 1999). The task requires the participants to solve a series of math operations while trying to remember a set of unrelated words. For example, the participants may see: "Is $(9 / 3)-1=1$ ? DoG." The participant is required to read the operation aloud without pausing and then to verify aloud whether the operation is correct ("yes" or "no"). After verification, the participant is required to read the word aloud, again without pausing. Once the participant reads the word aloud, the experimenter presses a key to move on to the next operation-word string. The same procedure is repeated until three question marks (???) appear, indicating to the participant that it is time to recall the words from that set in the correct order. The operation-word strings vary from two to five items in length. The Ospan score is the sum of recalled words for all perfectly recalled sets. In the present study, three sets of each length (two to five operation-word pairs) were presented to each participant, with possible scores ranging from 0 to 42 . In addition, to ensure that participants were not trading off between solving the operations and remembering the words, an $85 \%$ accuracy criterion on the math operations was required.

\section{Participants and Design}

The participants were 50 high and 50 low spans, as determined by the Ospan. Those participants were classified on the basis of a distribution of over 2,000 Ospan scores from our laboratory, with high spans falling in the upper quartile of the distribution and low spans falling in the lower quartile. The participants were recruited from a subject pool at Georgia Institute of Technology and from the Atlanta community through newspaper advertisements. They were between the ages of 18 and 35 and received either course credit or monetary compensation for their participation. Each participant was tested individually in a laboratory session lasting approximately $45 \mathrm{~min}$. The design was a 2 (span: high vs. low) $\times 2$ (instruction: incidental vs. intentional) $\times 2$ (sequence: random vs. repeating) $\times 12$ (block) mixed factorial design, with sequence and block as the only within-subjects variables. There were 25 high spans and 25 low spans in each instruction condition.

\section{Stimuli and Apparatus}

The stimulus consisted of an asterisk centered at one of four underlined horizontal locations. The asterisk and the underlined locations were presented in white on a black background. In the repeating condition, the sequence followed the predetermined hybrid sequence (see Cohen et al., 1990) of 4231342, with the numbers 1-4 representing the four different screen locations. The pattern repeated itself 10 times in one block of trials, with seven blocks overall, making a total of 490 sequence trials. In the random sequence condition, the asterisk followed a random sequence, with the exception that the asterisk could not appear at the same location twice in a row. There were five blocks of random trials, with a total of 350 trials, making a total of 840 experimental trials. The RSI was $300 \mathrm{msec}$. Responses were made by pressing one of four keys (F, G, H, J) corresponding to the location of the asterisk on the screen. All stimuli 
were presented and all data collected using a program written in E-Prime Version 1.0 on a PC.

\section{Procedure}

Serial reaction task. The participants were instructed to use the index and middle fingers on each hand so that the left fingers were positioned on " $F$ " and " $G$ " and the right fingers were positioned on " $\mathrm{H}$ " and "J," respectively. The participants also were instructed to respond as quickly and accurately as possible. The participants first encountered a block of practice trials in which the asterisk followed a random sequence for 63 trials. The practice trials were used to allow the participants to become familiar with the task as well as to lead them to think that all trials would be random. Following the practice trials, the participants performed one block of random trials followed by five blocks of repeating trials, switched to four more blocks of random trials and, finally, switched back to two blocks of repeating trials. The first block of random trials, similar to the practice trials, was used to discourage the participants from looking for a pattern within the sequence. To ensure that their results would not be confounded by fatigue, we gave the participants a 30 -sec break between blocks 4 and 5 and between blocks 8 and 9 .

Awareness assessment. After the participants finished the SRT task, they were told that sometimes the location of the asterisk followed a repeating pattern and sometimes it did not. The participants then filled out a questionnaire to assess their level of awareness. It consisted of three questions. The first asked whether they had noticed that the asterisk followed a pattern, the second asked whether they could indicate when they noticed that the asterisk followed a pattern, and the last asked whether they could describe the pattern. Next, the participants filled out a recognition form in which the correct pattern was displayed along with 23 incorrect patterns. The participants were instructed to indicate which pattern the asterisk had followed, and if they could not remember or if they did not know which pattern was the correct one, to simply guess.

\section{RESULTS}

\section{Participants}

The mean Ospan scores for the 50 high and 50 low spans were $24.10(S D=5.56)$ and $6.62(S D=2.24)$, respectively. In addition, the mean ages for the high and low spans were 22.74 years and 25.66 years, respectively.

\section{SRT Data}

Rate of learning. Overall, the accuracy in the SRT task was quite high. The mean accuracy rates for both high spans $(M=.969, S D=.023)$ and low spans $(M=$ $.964, S D=.028)$ were nearly identical, as were the accuracy rates for both intentional $(M=.964, S D=.025)$ and incidental $(M=.969, S D=.026)$ instructional conditions. The mean of the median RT for correct responses in each block of trials is shown in Figure 1, as a function of WM span and instruction. Note that high and low spans differed substantially in baseline RT for the task. Submitting the first block of random trials to an independentsamples $t$ test demonstrated that high spans were significantly faster $(M=392 \mathrm{msec}, S D=68.95)$ than were low spans $[M=485 \mathrm{msec}, S D=118.47 ; t(78.77)=$ $4.76, p<.01]$. Note that the variability for low spans was much greater than that for high spans, and thus the $t$ test is based on equal variances not assumed, which is indicated by the decrease in the degrees of freedom. On the basis of the large difference between high spans and low spans in baseline RT, the RTs were log-transformed for the statistical analyses. This served to move the RTs into the proportional measurement space, reducing the likelihood of finding a spurious interaction. This type of RT transformation is common in dealing with age differences in RT, but less so in dealing with WM span differences in baseline RT.

The data suggested that both high and low spans learned the pattern the asterisk followed in the patterned blocks, as indicated by a general decrease in their RTs across the experimental blocks and a subsequent increase in RT in the random blocks. In addition, high spans were faster than low spans, but the rate of learning for both high and low spans was equivalent under incidental learning conditions. That is, high spans were faster at the onset than were low spans, but the slopes for each group were equivalent, suggesting that both span groups learned the information at a similar rate. Under intentional learning conditions, however, high spans demonstrated a faster rate of learning than did low spans.

These conclusions were supported by a 2 (span: high vs. low) $\times 2$ (instruction: incidental vs. intentional) $\times 5$ (block: 2-6) mixed analysis of variance (ANOVA), with block as the within-subjects variable. The ANOVA yielded main effects of block $\left[F(4,384)=28.06, M S_{\mathrm{e}}=0.006\right.$, $p<.01$, partial $\left.\eta^{2}=.23\right]$ and span $[F(1,96)=26.93$, $M S_{\mathrm{e}}=0.93, p<.01$, partial $\left.\eta^{2}=.22\right]$. The main effect of instruction failed to reach significance $\left[F<1, M S_{\mathrm{e}}=\right.$ 0.006 , partial $\left.\eta^{2}=.004\right]$. Both the block $\times$ instruction and the block $\times$ span interactions were reliable [both $p$ s $<$ .01 , and both partial $\left.\eta^{2} \mathrm{~s}>.04\right]$. However, all of these effects were qualified by a significant three-way interaction involving span, instruction, and block $[F(4,384)=2.53$, $M S_{\mathrm{e}}=0.006, p<.05$, partial $\left.\eta^{2}=.03\right]$. This interaction suggested that high and low spans did not differ in the rate of learning under incidental learning conditions $\left[F<1, M S_{\mathrm{e}}=0.002\right.$, partial $\left.\eta^{2}=.016\right]$. Critically, under intentional learning conditions, high spans demonstrated a faster rate of learning than did low spans $[F(4,192)=$ $4.46, M S_{\mathrm{e}}=0.009, p<.01$, partial $\left.\eta^{2}=.09\right] .{ }^{1}$ Thus, as predicted, WM span differences only emerged under conditions that emphasized intentional processing.

Examining performance for high spans across the two instruction conditions suggested that high spans in the intentional learning condition had a faster rate of learning than did high spans in the incidental learning condition $\left[F(4,192)=4.51, M S_{\mathrm{e}}=0.009, p<.01\right.$, partial $\eta^{2}=$ $.09]$. For low spans, no such difference emerged $(F<1$, $M S_{\mathrm{e}}=0.003$, partial $\left.\eta^{2}=.01\right)$. Thus, it would seem that high spans benefited from the intentional instructions, whereas emphasizing the intent to learn did little for low spans relative to incidental learning instructions. Finally, an analysis of the four random blocks of trials following the sequence blocks revealed no significant interactions involving either span or instruction condition (all $p \mathrm{~s}<$ .15 and all $\eta^{2}$ s $<.02$ ).

Degree of learning. To better quantify the degree of learning of the repeating sequence, the mean difference 

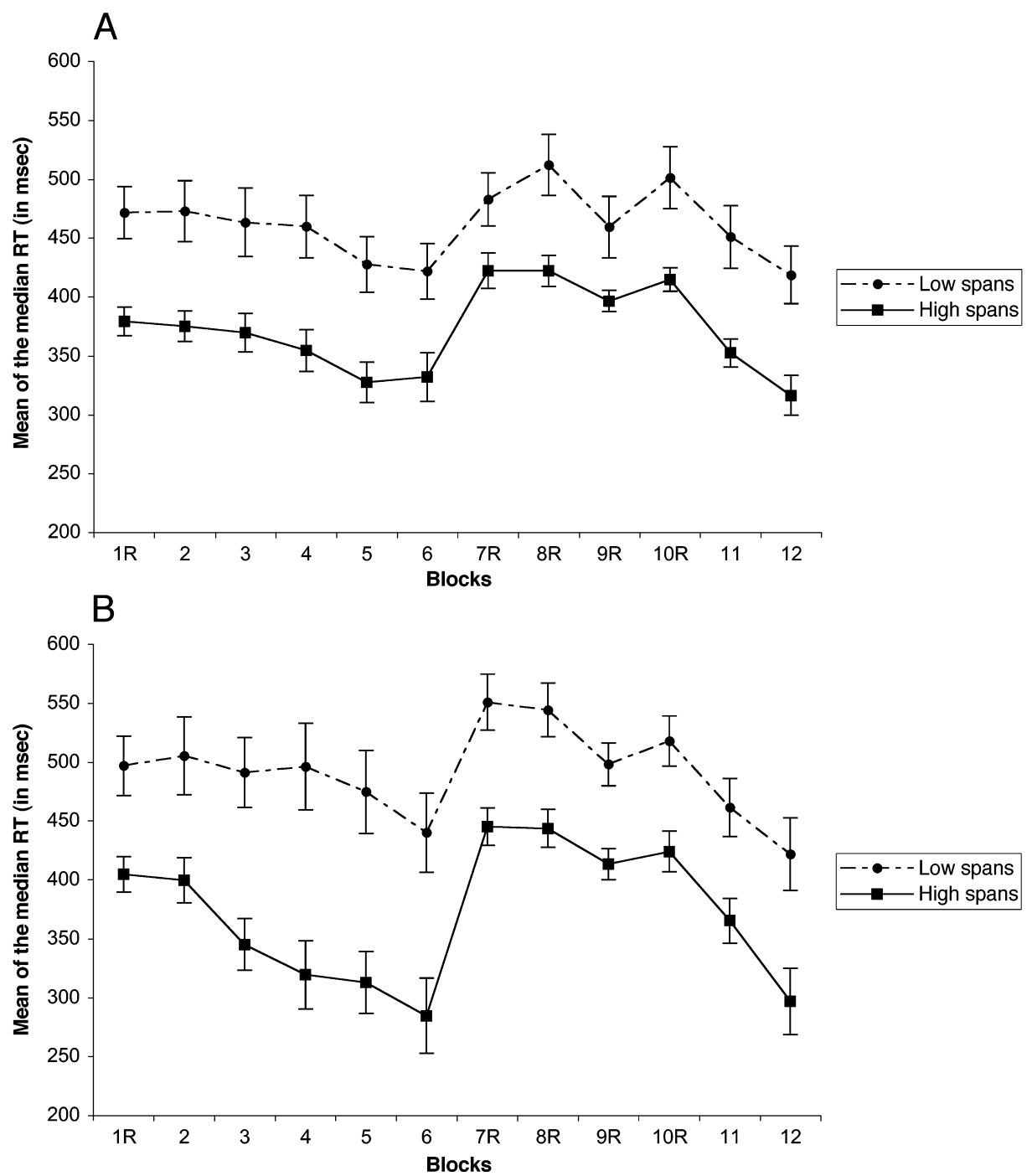

Figure 1. (A) Mean of the median RTs of correct responses for each block of trials as a function of span in the incidental learning condition. (B) Mean of the median RTs of correct responses for each block of trials as a function of span in the intentional learning condition. Error bars represent plus or minus one standard error of the mean. " $R$ " represents those blocks of trials in which the sequence was random.

in RT between the three blocks of sequence trials preceding the switch to random trials and the three blocks of random trials following the switch (i.e., blocks 4-6 and blocks 7-9; see Stadler, 1995) was examined. These values represent the difference in RT that occurs when participants switch from repeating trials to random trials. Therefore, planned comparisons were performed examining the differences between high and low spans on the difference score as a function of instructional group. As predicted, the analysis revealed that high $(M=73 \mathrm{msec}$, $S D=65.45)$ and low $(M=55 \mathrm{msec}, S D=53.88)$ spans did not differ in the degree of learning of the repeating sequence $\left[t(48)=1.09, p>.28\right.$, partial $\left.\eta^{2}=.024\right]$ under incidental learning conditions. Both groups learned the repeating pattern to some extent and learned the pattern to roughly the same degree. However, the degree of learning was higher for high spans $(M=121 \mathrm{msec}, S D=$ 103.05) than for low spans $[M=50 \mathrm{msec}, S D=105.04$; $t(48)=2.44, p<.05$, partial $\left.\eta^{2}=.11\right]$ under intentional learning conditions. Thus, although both groups demonstrated some learning of the pattern, high spans demonstrated far more learning than did low spans.

Comparing high spans' degree of learning in the two instruction conditions suggested that they learned more under intentional than under incidental learning conditions (mean difference $=48 \mathrm{msec}$ ). This effect approached significance $\left[t(48)=1.98, p<.06\right.$, partial $\left.\eta^{2}=.08\right]$. Examining low spans' degree of learning suggested no 
difference between the instructional conditions $[M=$ 5 msec; $t(48)=-.206, p>.83$, partial $\left.\eta^{2}=.001\right]$.

\section{Awareness Assessment Data}

To determine that high and low spans do not differ in implicit learning, it is important that the results be analyzed based on awareness, since any differences between high and low spans' scores may be due to differing levels of awareness. Therefore, the awareness measures administered after the SRT task were analyzed on the basis of span. For these measures, responses were scored based on participants' answers to the questions on the selfreport measure and the score on the recognition measure. For the self-report questionnaire, participants received 0 points for no description or for an incorrect description of the sequence, 1 point for correctly describing the sequence of length $3-5$, and 2 points for correctly describing the sequence of length 6-7 (Howard \& Howard, 2001; Seger, 1997). For the recognition measure, participants received 1 point for picking the correct pattern and 0 points for picking the incorrect pattern. Bivariate correlations revealed that the two awareness measures were reliably correlated $[r(100)=.71, p<.01]$. Therefore, on the basis of the correlation and the degree of similarity, these two measures were combined for analysis. Participants could receive a maximum of 3 points for the combination of the two measures. These values were then submitted to a univariate ANOVA with WM span and instruction as the between-subjects variables. The analysis yield a main effect of span $[F(1,96)=7.73$, $M S_{\mathrm{e}}=1.01, p<.01$, partial $\left.\eta^{2}=.08\right]$, with the high spans scoring significantly higher $(M=.94, S D=1.24)$ than did the low spans $(M=.38, S D=.72)$ on the awareness measures. The main effect of instruction approached significance $\left[F(1,96)=3.20, M S_{\mathrm{e}}=1.01, p<.08\right.$, partial $\eta^{2}=.03$, with intentional learners scoring slightly higher than did incidental learners $(M=.84, S D=1.17$, and $M=.48, S D=.87$, respectively). The interaction failed to reach significance $\left(F<1, M S_{\mathrm{e}}=0.002\right)$.

Next, participants were classified as being either unaware ( 0 points), or partially/fully aware (e.g., Howard \& Howard, 2001). On the basis of these classifications, 5 low spans and 10 high spans in the incidental condition were deemed to have some awareness of the relation during learning (leaving 20 low spans and 15 high spans who were unaware of the sequence). The possibly aware participants were dropped from further analysis, and the data were reanalyzed with the remaining unaware participants. The analyses yielded qualitatively similar results as before. High and low spans did not differ in either the rate of learning $\left(F<1, M S_{\mathrm{e}}=0.002\right.$, partial $\left.\eta^{2}=.006\right)$ or the degree of learning $\left(p>.67\right.$, partial $\eta^{2}=$ .006 ). Removing the aware subjects brought high and low spans closer together in terms of the degree of learning $(M=59, S D=61.68$, and $M=49, S D=59.17$, respectively). In addition, note that both of the partial $\eta^{2} \mathrm{~s}$ were much lower than before.

For the intentional learning condition, 9 low spans and 12 high spans were deemed to have some awareness of the relation during learning (leaving 16 low spans and 13 high spans who were unaware of the sequence). We dropped the unaware participants and reanalyzed the data. The analyses suggested that high spans were still faster in their rate of learning $[F(4,76)=3.80, p<.01$, partial $\left.\eta^{2}=.17\right]$ and demonstrated more learning $[t(19)=2.58$, $p<.05$, partial $\eta^{2}=.26 ; M=187, S D=89.35$, and $M=87, S D=84.04$, respectively] than did low spans. In addition, note that both of the partial $\eta^{2}$ s were much larger than before. Interestingly, although the participants were told of a pattern in the data, slightly more than half of them could not explicitly demonstrate any knowledge of it. This suggests the possibility that these awareness measures were not sensitive enough to detect differences in awareness of the pattern. This problem has been noted previously within the implicit learning literature (e.g., Stadler \& Roediger, 1998).

\section{DISCUSSION}

The primary question addressed in this study was whether WM capacity is important to incidental or intentional learning. The pattern of results observed suggests that high and low spans do not differ in the SRT task under incidental learning instructions (or if they do, the differences are very small) but do differ under intentional learning instructions. Our results are consistent with those of other studies that have demonstrated small to nonexistent individual differences (e.g., in aging) in implicit learning (Frensch \& Miner, 1994; Salthouse, McGuthry, \& Hambrick, 1999), but have shown that important individual differences emerge in the SRT under intentional learning conditions (Frensch \& Miner, 1994; Howard \& Howard, 2001). We take these results to suggest that individual differences in WM span become apparent when intentional control, and hence executive attention, is required.

In addition to demonstrating that span differences only emerge under intentional learning conditions, we wondered how this instructional manipulation would be related to a measure of higher order cognition. As noted in the introduction, one of the important aspects of WM span tasks is that they consistently predict performance on tasks of higher order cognition. Likewise, previous research has suggested that measures of incidental learning have small to nonexistent correlations with measures of higher order cognition such as reasoning, but that moderate correlations exist for explicit learning measures. In a large-scale (i.e., $N=455$ ) correlational study, Feldman, Kerr, and Streissguth (1995) found that incidental learning measures in the SRT had small to nonexistent correlations with a large battery of tasks including reasoning, processing speed, and STM. Declarative learning indexed via a generate task, however, demonstrated reliable correlations with virtually all of the measures, including intelligence (WAIS-R).

With this in mind, we wondered whether learning, as indexed by the degree of learning, would be related to higher level cognition as a function of task instruction. 
Because the majority of our participants $(n=96)$ had previously completed a measure of general fluid intelligence (Raven Progressive Matrices) in our laboratory, we correlated the degree of learning with the total correct score for participants in each instructional group separately. ${ }^{2}$ The analyses revealed a significant correlation between the degree of learning and general fluid intelligence $[r(47)=.48, p<.01]$ for the intentional learning participants, but a nonsignificant correlation for the incidental learning participants $[r(49)=.17, p>.24]$. Although based on somewhat small sample sizes, these correlations indicate that the amount of learning observed for the intentional learning group was related to a measure of higher order cognition but that the amount of learning in the incidental learning group was not. Note, however, that the differences in these correlations are due in part to differences in the amount of variability for the two groups ( $S D$ incidental $=60.06, S D$ intentional $=109.16)$. However, if incidental learning is a function of automatic processing, we would expect little variability among subjects and for this variability to be relatively unrelated to higher order cognition.

We have argued elsewhere that WM capacity is the ability to use executive (controlled) attention to actively maintain representations within the focus of attention (Engle \& Kane, 2004; Engle et al., 1999). Furthermore, although the relation between attention and implicit learning remains controversial, for the most part implicit learning seems to be an automatic process that operates without the use of the central executive. Thus, high spans are not always better at learning than low spans, but high spans demonstrate more learning when attention is engaged in learning. In addition, the results are inconsistent with models that suggest that individual differences in WM capacity are due to differences in overall activation levels (e.g., Just \& Carpenter, 1992) or to differences in the ability to set up temporary bindings of representations within the activated subset of memory (e.g., Oberauer, in press). Rather, the results suggest that an additional mechanism (what we have labeled executive attention) is responsible for individual differences in WM capacity.

In line with Cowan's $(1988,1995)$ model, we consider individual differences in WM capacity to correspond to differences in the efficacy of the central executive, which directs the focus of attention and "controls voluntary processing" (Cowan, 1988, p. 180). In this view, differences should only appear when voluntary intentional processing is engaged in, and not incidental processing. Indeed, Frensch and Miner (1994) have suggested that incidental learning occurs due to simple associations being made in STM that occurs without the use of the central executive in guiding the focus of attention. However, under intentional learning conditions, the focus of attention is engaged, via the central executive, to facilitate learning, perhaps through hypothesis testing. Under these conditions, not only is more learning demonstrated, compared with incidental learning, but WM span differences also begin to appear.

\section{REFERENCES}

BADDELEY, A. [D.] (1986). Working memory. London: Oxford University Press.

BuCHNER, A., \& WIPPICH, W. (1998). Differences and commonalities between implicit learning and implicit memory. In M. A. Stadler \& P. A. Frensch (Eds.), Handbook of implicit learning (pp. 3-46). Thousand Oaks, CA: Sage.

Cohen, A., Ivry, R., \& Keele, S. (1990). Attention and structure in sequence learning. Journal of Experimental Psychology: Learning, Memory, \& Cognition, 16, 17-30.

Conway, A. R. A., CowAN, N., \& Bunting, M. F. (2001). The cocktail party phenomenon revisited: The importance of working memory capacity. Psychonomic Bulletin \& Review, 8, 331-335.

Conway, A. R. A., \& Engle, R. W. (1994). Working memory and retrieval: A resource-dependent inhibition model. Journal of Experimental Psychology: General, 123, 354-373.

Conway, A. R. A., Tuholski, S. W., Shisler, R. J., \& Engle, R. W. (1999). The effect of memory load on negative priming: An individual differences investigation. Memory \& Cognition, 27, 1042-1050.

CowAN, N. (1988). Evolving conceptions of memory storage, selective attention, and their mutual constraints within the human informationprocessing system. Psychological Bulletin, 104, 163-191.

Cowan, N. (1995). Attention and memory: An integrated framework. Oxford: Oxford University Press.

Curran, T., \& Keele, S. W. (1993). Attentional and nonattentional forms of sequence learning. Journal of Experimental Psychology: Learning, Memory, \& Cognition, 19, 189-202.

ENGLE, R. W. (2001). What is working memory capacity? In H. L. Roediger III, J. S. Nairne, I. Neath, \& A. M. Surprenant (Eds.), The nature of remembering: Essays in honor of Robert G. Crowder (pp. 297314). Washington, DC: American Psychological Association.

Engle, R. W., \& Kane, M. J. (2004). Executive attention, working memory capacity, and a two-factor theory of cognitive control. In B. Ross (Ed.), The psychology of learning and motivation (Vol. 44, pp. 145-199). New York: Elsevier.

Engle, R. W., Tuholski, S. W., Laughlin, J. E., \& Conway, A. R. A. (1999). Working memory, short-term memory and general fluid intelligence: A latent-variable approach. Journal of Experimental Psychology: General, 128, 309-331.

Feldman, J., Kerr, B., \& Streissguth, A. P. (1995). Correlational analyses of procedural and declarative learning performance. Intelligence, 20, 87-114.

FrENSCH, P. A., \& Miner, C. S. (1994). Effects of presentation rate and individual differences in short-term memory capacity on an indirect measure of serial learning. Memory \& Cognition, 22, 95-110.

Frensch, P. A., Wenke, D., \& Rünger, D. (1999). A secondary tonecounting task suppresses expression of knowledge in the serial reaction task. Journal of Experimental Psychology: Learning, Memory, \& Cognition, 25, 260-274.

Heitz, R. P., UnSWORTh, N., \& Engle, R. W. (2004). Working memory capacity, attention control, and fluid intelligence. In O. Wilhelm $\&$ R. W. Engle (Eds.), Handbook of understanding and measuring intelligence (pp. 61-77). New York: Sage.

Howard, D. V., \& Howard, J. H., JR. (2001). When it does hurt to try: Adult age differences in the effects of instructions on implicit pattern learning. Psychonomic Bulletin \& Review, 8, 798-805.

Just, M. A., \& CARPENTER, P. A. (1992). A capacity theory of comprehension: Individual differences in working memory. Psychological Review, 99, 122-149.

Kane, M. J., Bleckley, M. K., Conway, A. R. A., \& Engle, R. W. (2001). A controlled-attention view of working-memory capacity. Journal of Experimental Psychology: General, 130, 169-183.

KANE, M. J., \& ENGLE, R. W. (2003). Working-memory capacity and the control of attention: The contributions of goal neglect, response competition, and task set to Stroop interference. Journal of Experimental Psychology: General, 132, 47-70.

KLEIN, K., \& FISS, W. H. (1999). The reliability and stability of the Turner and Engle working memory task. Behavior Research Methods, Instruments, \& Computers, 31, 429-432. 
Kyllonen, P. C., \& Stephens, D. L. (1990). Cognitive abilities as determinants of success in acquiring logic skill. Learning \& Individual Differences, 2, 129-160.

NisSEN, M. J., \& BUllemer, P. (1987). Attentional requirements of learning: Evidence from performance measures. Cognitive Psychology, 19, 1-32.

OBERAUER, K. (in press). Age differences and individual differences in cognitive functions. In R. W. Engle, G. Sedek, U. von Hecker, \& D. N. McIntosh (Eds.), Cognitive limitations in aging and psychopathology: Attention, working memory, and executive functions. New York: Oxford University Press.

Posner, M. I., \& SNYDER, C. R. R. (1975). Attention and cognitive control. In R. L. Solso (Ed.), Information processing and cognition: The Loyola Symposium (pp. 55-85). Hillsdale, NJ: Erlbaum.

Rosen, V. M., \& ENGLE, R. W. (1997). The role of working memory capacity in retrieval. Journal of Experimental Psychology: General, 126, 211-227.

Salthouse, T. A., McGuthry, K. E., \& Hambrick, D. Z. (1999). A framework for analyzing and interpreting differential aging patterns: Application to three measures of implicit learning. Aging, Neuropsychology, \& Cognition, 6, 1-18.

SCHNEIDER, W., \& SHIFFrIN, R. M. (1977). Controlled and automatic human information processing: I. Detection, search, and attention. Psychological Review, 84, 1-66.

SEGER, C. A. (1994). Implicit learning. Psychological Bulletin, 115, 163-196.

SEGER, C. A. (1997). Two forms of sequential implicit learning. Consciousness \& Cognition, 6, 108-131.

SHANKS, D. R. (2003). Attention and awareness in "implicit" sequence learning. In L. Jiménez (Ed.), Attention and implicit learning (pp. 1142). Amsterdam: Benjamins.

SHUTE, V. J. (1991). Who is likely to acquire programming skills? Journal of Educational Computing Research, 7, 1-24.
STAdLER, M. A. (1995). Role of attention in implicit learning. Journal of Experimental Psychology: Learning, Memory, \& Cognition, 21․ 674-685.

StADLER, M. A., \& Roediger, H. L. III (1998). The question of awareness in research on implicit learning. In M. A. Stadler \& P. A. Frensch (Eds.), Handbook of implicit learning (pp. 47-104). Thousand Oaks, CA: Sage.

Tuholski, S. W., Engle, R. W., \& Baylis, G. C. (2001). Individual differences in working memory capacity and enumeration. Memory \& Cognition, 29, 484-492.

TURNER, M. L., \& ENGLE, R. W. (1989). Is working memory capacity task dependent? Journal of Memory \& Language, 28, 127-154.

Unsworth, N., Schrock, J. C., \& Engle, R. W. (2004). Working memory capacity and the antisaccade task: Individual differences in voluntary saccade control. Journal of Experimental Psychology: Learning, Memory, \& Cognition, 30, 1302-1321.

\section{NOTES}

1. Note that the statistical analyses were rerun on the mean of the median RTs alone and covarying out differences in the first random block of trials. Both analyses yielded results that were qualitatively identical to the transformed analyses.

2. As part of the screening procedure in our laboratory, all participants are first given the operation span task and then the Raven Progressive Matrices. The Raven is used as our criterion measure of higher order cognition in various studies. Participants are brought back on the basis of their operation span scores only, thus allowing Raven to vary freely.

(Manuscript received January 21, 2004; revision accepted for publication June 15, 2004.) 